\title{
Arbor
}

\section{Un caballero español en Isfahán. La embajada de Don García de Silvia y Figueroa al sha Abbás el Grande (1614-1624)}

Joaquín $M^{a}$ Córdoba

Arbor CLXXX, 711-712 (Marzo-Abril 2005), 645-669 pp.

Uno de los libros más interesantes de los escritos por viajeros europeos a Oriente se debe a un español, Don García de Silva y Figueroa, embajador de Felipe III ante el sha Abbás el Grande de Irán. Pero como la muerte le sobrevino en su viaje de vuelta a España, impidiéndole publicar sus notas y recuerdos, lo cierto es que hasta comienzos del siglo XX no sería publicado su manuscrito completo en nuestro país. Desde entonces sin embargo, el valor de su figura y su obra no han hecho sino crecer. Además de la descripción apasionante que Don García hizo de los paisajes y pueblos por los que anduvo, su libro también supone la primera identificación cierta de Persépolis, y la primera propuesta de los signos cuneiformes como escritura de los antiguos.

A todos los compañeros con los que he compartido tantos años de estudio en Oriente. $Y$ en especial, a aquellos con los que he trabajado más tiempo, incluso en sitios vistos por Don García.

A Carmen, a Miguel Ángel y a Montse. A ellos y a todos los demás, gracias.

Era una tranquila y veraniega noche llena de estrellas, que la proximidad de las montañas del Elburz hacía singularmente agradable. En los inmensos jardines del palacio de Qazvin, en el centro de un gran estanque cuadrangular de mármol, mágicamente tallado en sus orillas por las luces 
de cientos de candiles de plata, que rielaban multiplicadas por las ondas de las aguas, sobre una elegante plataforma de tres gradas de piedra se levantaba un hermoso cenador, sustentado por cuatro grandes pilares de madera. En lujosas alfombras y cojines se acomodaban algunos magnates persas, vestidos y tocados a la rica usanza de la época safaví, un europeo de severa estampa, barba y cabellos blancos, con el gallardo traje de gala de la corte española, y un noble turco de albo turbante y túnica de raso leonado. Entre la brisa y la suave música que sonaba más allá de las luces que rodeaban el estanque, los comensales compartían una ligera cena compuesta por grandes platos de arroz, gallina y carnero, y otros de ciruelas, pepinos y rábanos. El gran señor que centraba la reunión vestía una sencilla aljuba de color verde. Mediano de cuerpo pero robusto, desde su perfil aguileño y enjuto dominaba la escena con el verdor de su vivaz mirada. Los comensales hablaban y reían, jugando con las palabras y las dudas de los intérpretes, posponiendo para más tarde las partidas políticas que debían trabar. Y es que aquella noche del 17 de julio de 1618, Don García de Silva y Figueroa, embajador de Felipe III de España, se encontraba al fin tras un largo viaje de casi cuatro años con el sah Abbás al Grande de Irán. Pero la luz de las candelas, el perfume de los jardines y la inmensa noche estrellada del momento con el que prologo el recuerdo de su aventura no es literatura caprichosa, sino su escenario cierto. Y así lo narró después nuestro embajador, con su prosa justa y contenida, en uno de los más bellos libros de toda la literatura europea de viajes a Oriente.

\section{De ediciones, manuscritos y libros}

Como no pocas veces a lo largo de nuestra historia cultural y política, malaventura y desidia se han unido para que la persona, los escritos y las aportaciones de nuestro caballero hayan tardado tanto en ser reconocidos. Sin embargo, hubo un admirado editor parisino, llamado monsieur De Wicqfort, que cuarenta y tres años después de la desgraciada muerte que impidiera al español culminar su tarea, publicó la traducción francesa de un manuscrito incompleto, L'ambassade de D. Garcia de Silva Figveroa en Perse ${ }^{1}$, que mereció cierta fama y estima, como revela la atención que le dedicara el célebre viajero Jean Chardin ${ }^{2}$. Pero la obra se sumiría luego en el olvido, entre el alud de nuevas publicaciones cada vez más completas y llenas de grabados magníficos dedicados a Irán, que la monumental recopilación de Antonio Invernizzi pone hoy de manifiesto ${ }^{3}$. 


\section{Un caballero español en Isfahán...}

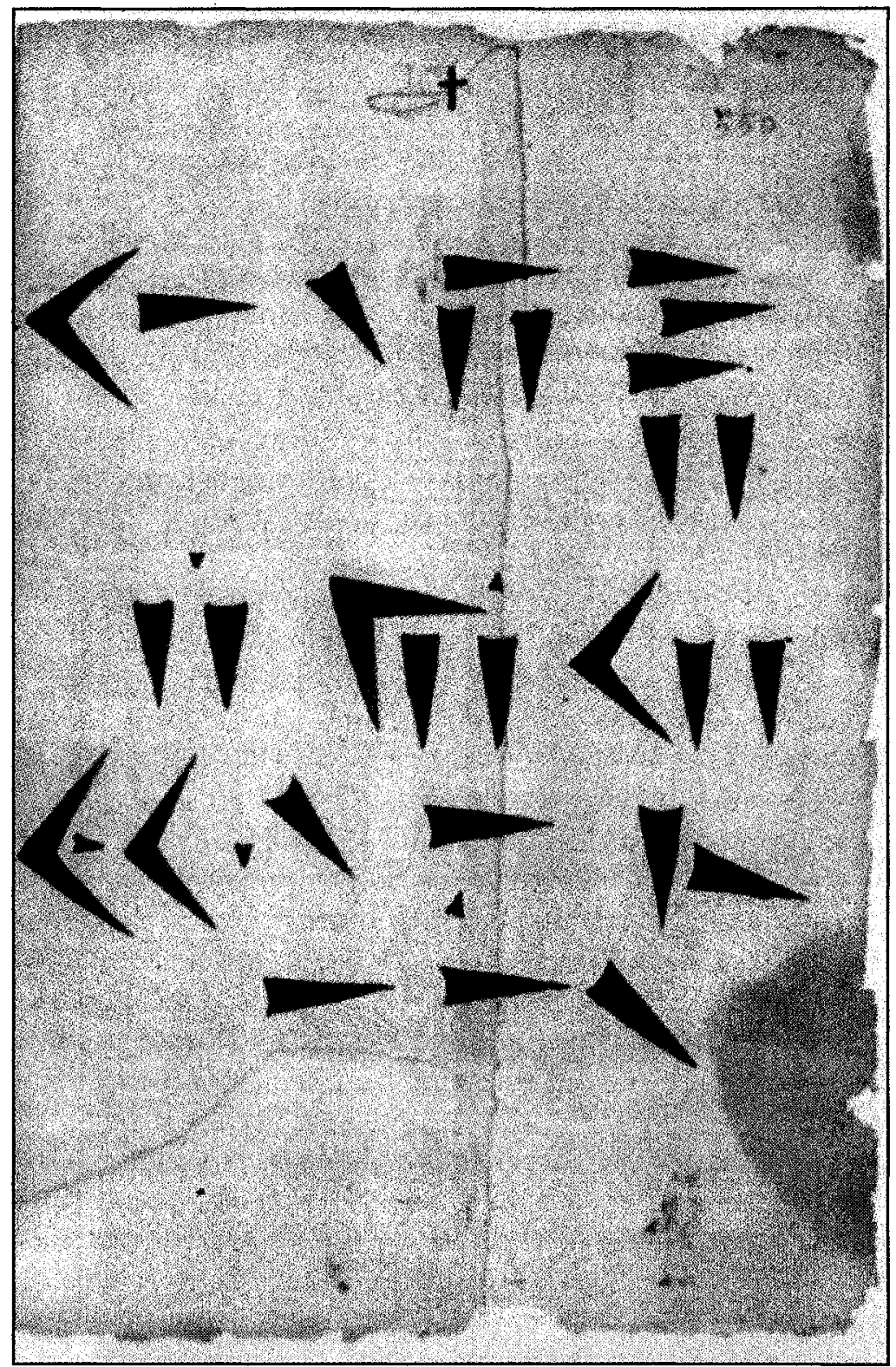

Figura 1. Copia de signos cuneiformes tomados en Persépolis, con ocasión del viaje de Don García. Se conserva en el manuscrito original

(según A. Invernizzi, 2001, fig. 30) 
La primera edición española del viaje y embajada de Don García de Silva y Figueroa hubo de esperar a los años 1903 y 1905. Fue su autor don Manuel Serrano y Sanz, que publicó el texto completo de uno de los dos manuscritos conservados en la Biblioteca Nacional (Ms 18217 y Ms 17629), ambos procedentes de la colección de Pascual Gayangos ${ }^{4}$. M. Serrano y Sanz se basó principalmente en el manuscrito 18217, que con acertado criterio consideró autógrafo de Don García de Silva, lleno de correcciones hechas por la misma mano a lo largo de los muchos años que debió tardar en escribir, releer y corregir esos impresionantes 546 folios conservados. Pero el editor decidió titular su publicación -también acertadamente-, con el que aparece en cabeza del otro manuscrito, el incompleto 17629, copia también fechada en el siglo XVII, que si falto de los primeros libros cierra sus 447 folios con una valiosa nota relativa a la muerte de Don García. En todo caso nos encontramos ante dos joyas de la cultura española, que se acompañan además de un mapa de Goa (éste sólo en el Ms 18217), con los primeros dibujos serios realizados sobre los relieves de Persépolis, y la primera copia de una inscripción de signos cuneiformes.

A partir de entonces, Don García de Silva ha ido poco a poco adquiriendo la fama y el lugar señero que le corresponde. A finales de los sesenta, en su estudio sobre viajeros olvidados a Persia, A. Gabriel lo citaba elogiosamente entre los más importantes ${ }^{5}$, aunque atendiera por extenso a otros verdaderamente olvidados. En 1989, Luis Gil recopiló una valiosísima colección de documentos relacionados con Don García de Silva, precedidos de un amplio estudio de las relaciones políticas entre Irán y España, a más de dos breves capítulos dedicados al mismo Don García y a su embajada ${ }^{6}$. Poco después, Heleen Sancisi-Weerdenburg recordaría la persona y obra del español, aunque guiándose por la antigua e incompleta edición de Wicqfort ${ }^{7}$. En 1993, Carlos Alonso publicó una muy completa e interesante biografía y relato de la misión en Persia $^{8}$, excelentemente documentada y de amena lectura. Para entonces Don García era ya objeto de frecuentes notas y aproximaciones académicas ${ }^{9}$, y recientemente A. Invernizzi le ha restituido en todo su valor, tanto en su excelente edición sobre Pietro della Valle -en la que analiza las dos series de dibujos de Persépolis conservados en los manuscritos de Madrid ${ }^{10}$-, como en la monumental antología de viajeros a Oriente, en la que incluso dedica más páginas al español que al inmortal noble romano ${ }^{11}$. La obra de Don García de Silva es un venero de información, que apenas si ahora estamos empezando a valorar ${ }^{12}$. Ante las dificultades editoriales que supone aún la edición completa de su obra, una próxima antología dará idea al menos de los hallazgos y las aventuras más señaladas de uno de nuestros más importantes viajeros a Oriente ${ }^{13}$. 


\section{Si no una biografia, algo más que una sombra entre la bruma}

Vienen a decir cuantos emprenden la biografía de Don García de Silva y Figueroa, que es notablemente poco lo que se conoce ${ }^{14}$. Y es verdad si nos atenemos al elenco de papeles fechados, pero de la vida de un hombre que sabemos nacido el 29 de diciembre de 1550 en Zafra, bajo el reinado de Carlos V, y muerto a los 75 años de edad, el 22 de julio de 1624 y en la inmensidad del océano Atlántico, cuando ya gobernaba Felipe IV, podemos reconstruir mucho más de lo que cabría suponerse en principio, si a los datos seguros, la documentación de los archivos y la magna amplitud de su obra escrita sumamos las legítimas deducciones que sus cartas y sus recuerdos nos permiten colegir. $Y$ aunque no podamos decir que tengamos un retrato minucioso, sin duda conseguimos recuperar el perfil de un ser concreto, que nos produce la gozosa alegría del que ve surgir de entre las brumas, la imagen del ser querido al que buscaba.

Una cierta nobleza en su origen se advierte, como hijo de Don Gómez de Silva y Doña María de Figueroa, emparentados con los condes de Zafra, y al ser su padrino Don Pedro Fernández de Córdoba, conde de Feria, y su madrina la hija del mismo conde Doña Catalina ${ }^{15}$. Hasta su toma de posesión como corregidor de Jaén el 7 de marzo de 1595, todavía al menos ignoramos cualquier otro documento que le cite, pero los 46 años con los que entonces contaba, la fácil concesión real del cargo, la autoridad puesta en su gestión, la eficacia demostrada en asuntos militares y cuanto luego apuntaremos, revela que las antiguas atribuciones puestas en duda -que había sido paje de Felipe II, estudiado leyes en Salamanca y servido en los Tercios de Flandes ${ }^{16}$ - no tienen por qué ser inciertas: el mayor de varios hermanos y protegido de un Fernández de Córdoba podría haber sido paje, estudiado leyes y desde luego marchado como tantos otros a Flandes. Es obvia su profunda cultura y su dominio de lenguas -al menos y perfectamente, el latín y el italiano ${ }^{17}$-, sus buenas relaciones en la corte y la necesidad en que se encuentra acaso a su vuelta a España -como sabemos de tantos otros hidalgos y soldados en Flandes, Italia o Alemania-, y puede que al igual que otros muchos pidiera merced de un cargo que sus orígenes y buenas relaciones en la Corte debieron facilitar, y al mismo rey Felipe II y ya como corregidor en Jaén, es seguro que demandó ayuda en las apreturas de su mayorazgo con hermanos a cargo ${ }^{18}$. En el fondo, una biografía muy común entre la pequeña y media nobleza de la España de los siglos XVI y XVII, por tanto perfectamente defendible incluso con los parcos datos disponibles. Sus buenas dotes militares y su energía y capacidad organizativa se demos- 
traron en la puesta a punto de una fuerza armada contra los ingleses en 1596, y en la buena dirección y adiestramiento que él mismo encabezó. Y aunque la provisión del cargo de corregidor solía ser anual, Don García permaneció dos años en el mismo, lo que revela que sus servicios administrativos y militares fueron bien estimados, y que debía contar con una cierta protección en la corte.

Ignoramos a dónde fue después, pero las antiguas semblanzas ${ }^{19} \mathrm{di}-$ cen que prestó servicios en la Secretaría de Estado, lo que pudiera haber hecho tras su cese como corregidor en los primeros meses de 1597 o algún tiempo después, acaso una vez ordenada la economía de su mayorazgo. El caso es que en 1609 estaba en Madrid, y el marqués de Velada, Mayordomo Mayor y del Consejo de Estado, le consultó sobre los supuestos descubrimientos geográficos de Lorenzo Ferrer Maldonado ${ }^{20}$, lo que indica a mi parecer dos cosas: que personal, administrativa y políticamente estaba muy cercano al Consejo de Estado, y que sus conocimientos geográficos eran estimados hasta el punto de tener valor de dictamen facultativo. $\mathrm{Y}$ es lo cierto que como se podrá leer luego en el relato de su viaje, además de manejar personalmente todo tipo de instrumentos, su visión del mar, las estrellas y las tierras es la de un geógrafo y cosmógrafo.

Así las cosas nos encontramos con que tras las embajadas de Anthony Sherley, los frailes agustinos y Don Luis Pereira, las gestiones de Fray Antonio de Gouvea, los movimientos de Robert Sherley ${ }^{21}$ y la necesidad de prevenir las ambiciones iraníes sobre los presidios portugueses y relanzar la antigua alianza contra el turco, el Consejo de Estado se reunió el 2 de octubre de 1612, ante la necesidad de enviar al sha Abbás una gran embajada de calidad y del más alto rango. Y sin duda el largo historial que intentamos reconstruir, que trasluce nobleza, madurez diplomática y política, amplios y variados conocimientos y un evidente reconocimiento en la corte, explica el nombramiento de Don García de Silva y Figueroa, que a sus sesenta y dos años cumplidos aceptó por su misma mano el 19 del mismo mes $^{22}$.

La preparación de la embajada fue larga y fatigosa, en gran medida por la mala voluntad del Consejo de Portugal -dolido por la elección de un castellano-, dándose así inició a la que sería causa mayor de los retrasos sufridos por el embajador, la ineficacia misma de la embajada y el calvario que hubo de soportar en su relación con virreyes, oficiales y frailes portugueses hasta su tan tardía y nunca alcanzada vuelta a España, diez años después de su salida. Pero el caso es que con la constancia y previsión de la dignidad e importancia que la gestión encomendada pre- 
cisaba, Don García consiguió hacerse a la mar en abril de 1614 . Y pese a todos los sabotajes y desplantes alcanzó a entrevistarse con el sha Abbás de Irán en 1618, mantuvo una constante remisión de informes dirigidos al rey, escribió una maravillosa relación de su viaje, descubrió que Chilminara había sido Persépolis y los signos cuneiformes escritura de los antiguos persas, contempló y describió la cultura del Irán y sus costumbres, monumentos y paisajes, y se reveló como uno de los más humanos, curiosos, capaces y valerosos hombres de su tiempo. Mas la fortuna no quiso que llegara a volver a España, como tanto ansiaba, pues murió en alta mar el 22 de julio de 1624, cuando casi se sentían los vientos y corrientes que llevaban a la península. Y si su semblanza se cierra así, creo yo que si no una biografía, algo más tenemos que una sombra entre la bruma.

\section{Los Comentarios de Don García de Silva y su aventura más extrema}

Aunque apasionantes e intrincados los problemas de la política internacional de la época y el papel de España e Irán en la misma, y sorprendentes los forcejeos entre la Corona y el Consejo de Portugal y las autoridades lusas en la India ${ }^{23}$, por fuerza hemos de centrarnos aquí en la descripción del viaje y sus aportaciones al redescubrimiento de Oriente y del Irán antiguo y el que le fue contemporáneo a nuestro viajero, porque su libro es un monumento de la literatura española y europea de viajes. El Ms 18217 de la Biblioteca Nacional al que antes me refería, sin duda autógrafo, fue base de la edición de M. Serrano y Sanz, que en su advertencia inicial aclara que como Don García de Silva había ordenado sus recuerdos en "libros", los dividió él en capítulos y "puesto epígrafes en éstos para mayor comodidad de los lectores" ${ }^{24}$. Vamos pues a seguir su viaje, intentando no recargar de notas innecesarias lo que no aspira a ser más que un resumen apresurado de una aventura y un libro portentosos.

\subsection{Levando anclas en Lisboa. De la mar, los barcos y los inmensos océanos}

El largo viaje por mar de Don García y su séquito, hasta su primer destino en Goa, duró casi siete meses de navegación constante, sin to- 
car jamás tierra, según la vieja «volta grande» de los pilotos portugueses de la carrera a la India ${ }^{25}$. El martes 8 de abril salieron de Lisboa tres naves, en cuya capitana, Nuestra Señora de la Luz, iban el embajador con los suyos y el armenio Cogelafer, enviado del sha. Guiaba la flota el piloto mayor Gaspar Ferreira, que decidió al principio navegar a media vela para dejar que se les unieran otras dos naves rezagadas. Siguiendo vientos de suroeste, el día 14 se avistó la isla de Puerto Santo, y el 15 se dejó Madeira por estribor, tomándose luego rumbo sur, con todo el velamen desplegado en busca de las Canarias, que el 17 se fueron perdiendo a su vez por babor. Como era costumbre entonces, se abrieron los pliegos reales con las instrucciones del viaje, en los que se dejaba al criterio del Piloto y Maestre aguardar a los rezagados o seguir avante. Hecha consulta a los prácticos se resolvió continuar, ante el temor a perder los vientos y corrientes favorables, y no poder llegar a la India aquel año. $Y$ desde ese momento comenzó la verdadera gran navegación.

La «volta grande» era fruto de la experiencia naval lusa en sus viajes por el Atlántico y el Índico. Sabían que al Oeste de Canarias, los alisios y las corrientes les permitían cruzar el Ecuador por la parte más estrecha del Atlántico, en dirección a la costa del Brasil; que allí, a la altura del Cabo de San Agustín, debían mantener rumbo suroeste hasta los Baixios de los Abrolhos. Y que desde éstos, navegando hacia el sureste, habían de alcanzar la altura de la isla de Tristán de Acuña, pues manteniendo luego el rumbo superarían el Cabo de Buena Esperanza, entrando al Océano Índico. Pasado el temible escollo, los pilotos elegían según circunstancias navegar por fuera o por dentro de la Isla de San Lorenzo (Madagascar), y luego fijaban rumbos hasta que más al norte del llamado Cabo Guadalfui, tomaban los vientos que les llevaban directamente a $\mathrm{Goa}^{26}$. En las páginas escritas por Don García, tan tremendo viaje resulta un relato apasionante, escrito por alguien que parece al tiempo un marino, un geógrafo, un naturalista y un astrónomo enamorado de las constelaciones.

La navegación y las tormentas, los animales marinos y las aves, los problemas de los buques y la marinería, todo fue llamando la atención del viajero. Así, el día 30 dice que se tomó el sol en menos $8^{\circ}$, pero que como estas medidas las tomaban los pilotos con astrolabios tan pequeños que impedían afinar, se cometían grandes errores de posición. Ese mismo día entraron en calmas y notaron que les seguían la estela gran cantidad de tiburones, que Don García describe con todo detalle en su aspecto y comportamiento, lo mismo que más adelante, ya en- 
trado el mes de junio, el de las grandes manadas de delfines. La navegación iba mal, tanto por la tardanza en hacerse a la mar aquel año como por el poco concierto de los pilotos: el gobierno interno tampoco era bueno, pues el autor señala el excesivo consumo de agua potable, la mala estiba y el deficiente gobierno del timón, la sobrecarga y la suciedad del casco. Pero la navegación seguía con todo, y el 25 de junio empezaron a verse las constelaciones australes. Extasiado el embajador, tras recordar las estrellas y constelaciones que ha ido observando desde su salida de la península y la progresiva pérdida de la Polar, comienza a describir las del sur, destacando la que llama "Cruçero", grupo de nueve estrellas de las que la principal es "muy hermosa y luçcida y la mayor de este Hemisperio Austral». Poco después avistaron enormes ballenas, y el 3 de julio grandes cuervos, uno de los cuales quedó enredado en la jarcia dando ocasión a que el embajador lo examinara y describiera, mandando luego dejarlo libre sin daño ${ }^{27}$, en un gesto de natural mansedumbre con los animales, repetido muchas veces a lo largo de sus recuerdos. El 15 de julio notaron ya gran frío, y tomando el sol en $31^{\circ}$ pensó el piloto hallarse un poco al este de la isla de Tristán de Acuña, a unas trescientas cincuenta leguas del Cabo de Buena Esperanza. Pero se equivocaba en demasía -en más de 400 leguas, como luego se vería-, pues en realidad se encontraban todavía muy al oeste de aquella isla, de referencia vital en la navegación portuguesa a la India. Los vientos se hacían cada vez más fieros y el gobierno de las naves se complicaba por los crecientes oleajes, temporales y aguaceros. El día 25 cundió el desconcierto entre los pilotos, pues según su parecer debían haber doblado ya el cabo, aunque no hallaban señales de tierra. La situación le dio pie a substanciosos comentarios sobre la arrogancia, envidias y obcecaciones de los pilotos de la carrera, así como de la continua competencia entre ellos, causa repetida de muchas desgracias y naufragios. El 10 de agosto avistaron por vez primera grandes lobos marinos, y por éste y otros indicios pensaron hallarse ya por fin cerca del cabo de Buena Esperanza, que el día 12 se confirmó doblado, iniciándose al fin la navegación por el Índico en busca de la India. Dadas las fechas se resolvió navegar por fuera de la Isla de San Lorenzo (Madagascar), huyendo de peligros más frecuentes por el interior en esa época del año, causa de tantas calamidades. El 20 de agosto se tomó el sol en $36^{\circ}$ y a doscientas leguas de la costa de la Tierra de Natal. Siguióse avante el rumbo y el 1 de septiembre estimó el piloto correr ya entre los bajos de Grajao, lejos de San Lorenzo. Pero se equivocó otra vez. A esas alturas de la marea, el número de enfer- 
mos se había hecho muy numeroso, y Don García se detiene a describir las enfermedades más corrientes, en especial la más terrible y que entonces llamaban "Mal de Loanda" -en realidad el escorbuto del que él mismo había de morir años después,-- que en su opinión el cirujano trataba erróneamente. El 2 de octubre entraron en calmas y calores, tornados en aguaceros, lo que dificultó más la situación de los muchos enfermos y aumentaron las muertes. El día 13 se navegó este-nordeste en demanda de la isla de Mamale, a 40 leguas de la ciudad de Cochin en la costa india. Pero estaban lejos, y además de las angustias de la navegación, las enfermedades y los problemas de alimentación, una plaga de ratones infestaba las naves. El día 21 avistaron barcas de naturales de Mamale y hablaron con ellos, tomando alguna noticia y sobre todo certeza de la proximidad del fin de tan duro viaje. El 29 se iba navegando ya a la vista de la costa de la India, y al día siguiente la Capitana amaneció a cuatro leguas de tierra, viendo a babor el monte Delhi. La ruta a Goa estaba ya tan cerca que tras algún susto de última hora en bajos y arrecifes, el día 6 de noviembre se avistó la punta de la isla de Goa y "blanquear en ella la iglesia y deuocto conuento de Nuestra Señora del Cabon. Fueron entrando en el surgidero y muchos navíos y barcas de la población local acudieron a visitar parientes y amigos a los que esperaban, y a ofrecer agua fresca y frutas, alegrándose todos de la feliz arribada. Don García escribió que aquel día, anclando frente a la fortaleza de la Aguada era "jueues á seis de Nouienbre de 1614, siete meses continuos menos dos días despues que esta nao, .... salio de la barra de Lisboa». La primera parte de su aventura estaba cumplida ${ }^{28}$.

\subsection{La estancia en Goa. Delicias y dolores en la India portuguesa}

Una vez en la capital del imperio luso de la India, cabeza de todos sus presidios en las costas de Arabia, Irán y el Golfo Pérsico -como siglos después lo sería Bombay del de los ingleses-, Don García comenzó el segundo periodo de su largo viaje, limitado en este caso a una desesperante retención en la ciudad. En cualquier caso pudo vivir así las delicias y los dolores de la estancia en la India portuguesa.

En el libro segundo de sus recuerdos leemos la descripción del entorno, la ciudad y sus habitantes y costumbres, y en el tercero, tras una contenida referencia a sus problemas con el virrey, la continuación del viaje hasta la costa de Arabia ${ }^{29}$. Pero en el interim habían pa- 
sado más de dos años de forzosa residencia, tiempo que el embajador aprovechó para mantener una larga e interesante correspondencia con el rey ${ }^{30}$, y redactar sus primeras notas, que fecharía a punto de partir por fin, en «Goae Orientalis Maritimaeque Indiae Metropolis, Nonis Ianuarii, anno 1617\%. Goa era un asentamiento privilegiado, un pequeño conjunto en realidad de islas de unos $3.400 \mathrm{Km}^{2}$, la mayor de las cuales era la que llamaban estrictamente Goa, y que se percibe bastante bien en el mapa que el Ms 18217 de la Biblioteca Nacional conserva ${ }^{31}$. El manuscrito describe la topografía de la principal, empezando por su extremo más occidental, el cabo Talangan, donde se alzaba el convento de Nuestra Señora del Cabo. Al sur del mismo se abría el surgidero más seguro para los navíos, con la playa y las ruinas de la antigua ciudad ya abandonada: al norte, el gran canal del río Pangin, que llevaba directamente a la ciudad nueva construida por los portugueses, aunque su estuario tenía un gran banco de arena que los pilotos debían conocer bien, y que en invierno cerraba la barra. A una y otra orilla se levantaban árboles pequeños y frondosos, tras los cuales se alzaban multitud de palmeras. En esa orilla de la isla se veían dispersas casas de portugueses y naturales cristianos, entre los palmerales y cultivos que se sucedían sin interrupción hasta la misma ciudad, tras la que se alzaba la gran fortaleza de Daugin. Luego, hacia el nordeste, este y sureste de cara a islas menores y la tierra firme, corría la obra de un gran baluarte. La vuelta a la isla -en cuyo centro, las rocas de una gran sierra servían como cantera para la construcción- acababa de nuevo en el estuario del surgidero, con la hermosa playa de Guadalupe, a cuya orilla, entre arbolados y palmeras se abrían otras muchas quintas de portugueses y casas de pobladores del país. Don García atendió también a describir los animales y plantas propias de Goa: entre los primeros, una especie de hienas, algunos lobos, tres tipos de serpientes y una suerte de lagartos muy mansos que "llamanles los portugueses camaleones, aunque no mudan su color, tomándola, como se dize comunmente, de las cosas cercanas á ellos, teniendo siempre estos de la India el suyo propion. Maravillábale la frondosidad de los palmerales y árboles cargados de fruta, describiendo el mango, y otras de tamaño "mayores que grandes melones», de cáscara verde y rugosa y carne amarillenta. Habla de otras muchas frutas más comunes, como las cidras, limones y naranjas y lo que "llaman los portugueses higos de la India, y sus naturales quelen; son propiamente los plátanos de nuestras Indias Ocçidentales». Alaba también otros grandes árboles de la isla y los cultivos de legumbres, hortalizas y verduras. 
Naturalmente, el embajador describe la ciudad principal, que dice ser de buenas casas pero muy desordenada, destacando la fortaleza y palacio de los virreyes, algunos ricos y suntuosos conventos y parroquias con tal calidad y grandeza que «se puede comparar esta çiudad, ansi en grandeza, ornato y suntuosidad de tenplos, como en número de religioso y eclesasticos, con muchas de las mas çelebres ciudades de Europan. Señala los barrios y sus características, como el de San Matías, la plaza de Peuloriño y la gran plaza de Leylan, la más frecuentada de todas, entre la catedral y la rua Derecha, sitio de feria y mercado muy animado, o los edificios que le parecieron más notables, como el convento de Santo Domingo y la Casa Profesa de la Compañía de Jesús.

La ciudad y la isla formaban un mundo abigarrado, y los portugueses, los mestizos y los naturales de la India daban vida a una sociedad alegre, cuyos hábitos asombran a veces al severo y ya provecto embajador. Pero seguro que para aquellos que habían navegado siete meses de peligros sin cuento, la ligereza de costumbres y la vistosidad de los trajes femeninos, tanto los de las naturales como los usados por las portuguesas allí afincadas, debían antojárseles visión del paraíso recobrado. Así, la convivencia de portugueses, mestizos, cristianos naturales y población de "banianes y bramanes" ofrecía magnífico espectáculo. Los portugueses y mestizos vivían del comercio, sin hacerse distinción ni rechazo alguno y participando igualmente en la administración, la milicia y las actividades de la mar. Los cristianos naturales vivían en el campo sobre todo, trabajando en la agricultura. Las mujeres del país vestían una prenda que nos sugiere el atractivo shari, y las damas lusas solían llevar ligeras blusas casi transparentes, con generosos escotes que provocaron el asombro del embajador. Luego, Don García comenta los usos y creencias de los bramanes, la veneración por las vacas, la lengua del país y su singular escritura, un "alphabeto, que es de figuras muy perfectas, semejantes a las de la lengua armenica», la creencia en la trasmigración de las almas en seres humanos y animales, las penitencias de los yoguis y muchas otras cosas curiosas que el espacio impide incluso resumir.

La estancia en Goa no le fue sin embargo demasiado placentera, urgido en su misión que cada día saboteaba el virrey. En todo caso, en sus recuerdos es discreto en el tono, aunque escribe que cansado de retrasos y engaños «se enbarcó en una naveta de un mercader de Baçain, de menos de dozientas toneladas, sin artilleria ni soldados, con sola la gente de su familia y veinte marineros moros», y se hizo a la mar el 19 de marzo de 1617. 


\subsection{Embajador de España en Irán. El viaje y sus sorpresas}

Rumbo noroeste y a toda vela, la nave del embajador fue cruzando el Océano Índico hacia la costa de Arabia, que se avistó por fin el 8 de abri ${ }^{32}$. Escribe Don García que el calor era ya muy grande, y la visión de la tierra tristísima, de «color arena bermeja, sin parecer en ellas cosa verde alguna, $n i$ señal de ser habitadas». La navegación siguió hacia el nordeste, en paralelo a la costa, y con fecha del día 15 hizo una referencia que no me resisto a citar. Al amanecer distinguieron sobre las montañas de la costa omaní lo que los marinos portugueses llamaban «palleiros», "ciertos montes que pareçen sobre las cumbres de las montañas,........y son estos montecillos tres ó quatro»: en mi opinión, sus notas son la primera referencia conocida en la literatura de viajes a ciertas sepulturas preislámicas muy típicas de la Península de Omán ${ }^{33}$. Un día después, la nave doblaba el cabo de Roçalgate -probablemente el hoy llamado Ra's al Hadd-, pues dice que al hacerlo durante la noche se apartaron mucho de tierra. Recuperado el rumbo, el piloto fue siguiendo la costa a favor de los vientos, ahora en dirección noroeste, hasta que el 19 divisaron las montañas próximas a Mascate, donde el embajador desembarcó al siguiente día. La mar dificultó la entrada del buque en el asombroso puerto de Mascate, un capricho de la naturaleza rodeado de riscos fragosos, coronados ya por fortalezas inexpugnables y todavía hoy impresionantes. Siendo lugar tan importante en la costa, la sencilla población árabe vivía en unas trescientas cabañas del tipo barashti-según la descripción de Don García-, destacando sólo algunas casas de portugueses de piedra y cal, y tiendas de indios y banianes junto a la parroquia, al pie de la fortaleza, que visitó minuciosamente. Muy pocos lusos, comerciantes y algunos soldados, la mayoría de la población de Mascate estaba compuesta por árabes y algunos judíos. El día 22 se hicieron de nuevo a la mar. La navegación era cada vez más difícil: el 26 divisaron el islote de los Ratones, indicio cierto de la proximidad de Musandán, y tres días después llegaron a Ormuz, isla del estrecho y a dos leguas de la costa de Irán. Llave de la entrada al Golfo Pérsico, la isla y ciudad de Ormuz constituían pieza decisiva del mapa portugués de la región, pero el embajador descubrió la debilidad de sus baluartes y su mala conservación. Poblada por unas «quarenta mil almas», Ormuz seguía desarrollando un activo comercio, y entre los habitantes cristianos, árabes e indios halló algunos sefardíes, que todavía hablaban español. Por la misma razón que en Goa, el embajador hubo de detener su viaje hasta el 12 de octubre, cuando embarcado en la galera San Francisco cruzó la mar restante y desembarcó finalmente en la costa de Irán, siendo recibido por el gobernador de la fortaleza de Bandel «con grandes demostraçiones de cortesicor. Por fin comenzaba su verdadera embajada y entraba en contacto con los per- 
sas, cuyos trajes, modales y atenciones alaba reiteradamente. Tras algunos días precisos para reunir los caballos y camellos que su séquito precisaba, se puso en marcha por la antigua y seca Carmania, parando en caravansares como el de Guichi, y recibiendo agasajos y regalos de gobernadores locales, como el muy joven y atento de Cabrestán. Poco a poco empezó a entrar en las tierras altas y los valles de los Zagros, mejorando notablemente el paisaje y el arbolado. El 28 de octubre llegó a la ciudad de Lara, siendo recibido a media legua de ella por su gobernador, Chanberbec, «con mucha gente á cauallo, muy luzida de caballas ó aljubas de sedas de varias colores y tocas de oro, con çimitarras y puñales guarneçidas de oro y platoß. La ciudad de Lara le pareció semejante a la de Ormuz, con edificios de adobe y algunas de las mejores casas dotadas con lo que llama "catauientos», refiriéndose sin duda a la típica "torre de ventilación" de la arquitectura de Irán y las costas árabes del Golfo Pérsico. Le llamó especialmente la atención la plaza del Bazar, que consideró comparable a muchas de las más famosas de Europa, y cuya vitalidad comercial y mercancías le maravillaron, deteniéndose con atención en todo. Y tras los habituales agasajos y comidas con el gobernador, el 9 de noviembre continuó la marcha hacia el interior. Todo el camino va siendo minuciosamente descrito, entrando en los valles, comprando carneros a pastores turcomanos -cuyos tipos, trajes y costumbres describe, incluso trayendo a colación datos de su historia-, comentando de ciudades menores y campamentos además de algunas curiosas anécdotas, hasta que el 24 de noviembre hizo su entrada oficial en la ciudad de Shiraz. Al principio, casas y calles no le llamaron la atención, hasta que llegó a una gran plaza en la que se estaba acabando de construir una «sumptuosissima mezquitco», y alojado en un palacio que poseía una gran sala «mayor que ninguna de la Casa Real de Madrid", con vidrieras, muros enlucidos de cal y muchas figuras de mujeres pintadas en los muros, cuyos vestidos y estilo le hicieron pensar en maestros italianos. Desde los miradores tenía magníficas vistas de los jardines y la ciudad, distinguiendo sus paseos y avenidas plantadas de árboles espléndidos, asombrado también ante la enorme cantidad de rosales cultivados, de cuyas flores se destilaba un agua que llegaba hasta la India y países mucho más lejanos. Permaneció Don García en la ciudad hasta la primavera del año siguiente, por los rigores del invierno y por hallarse el sha en la costa del Caspio, hasta que un 4 de abril prosiguió su marcha camino de Isfahán. Sin embargo, a pocas leguas de Shiraz se apartó un poco de la ruta, por el deseo que tenía de ver las ruinas de Chilminara. $\mathrm{Y}$ «por ser este sitio, sin poderse poner duda alguna en ello, el de la antigua Persepolis», tomó su latitud el 7 de abril de 1618. Aunque no lo supiera o quisiera darle el valor que su descripción y conclusiones en realidad tienen, el noble viajero español acababa de llegar a su cita con la Historia. 


\section{Un caballero español en Isfahán...}

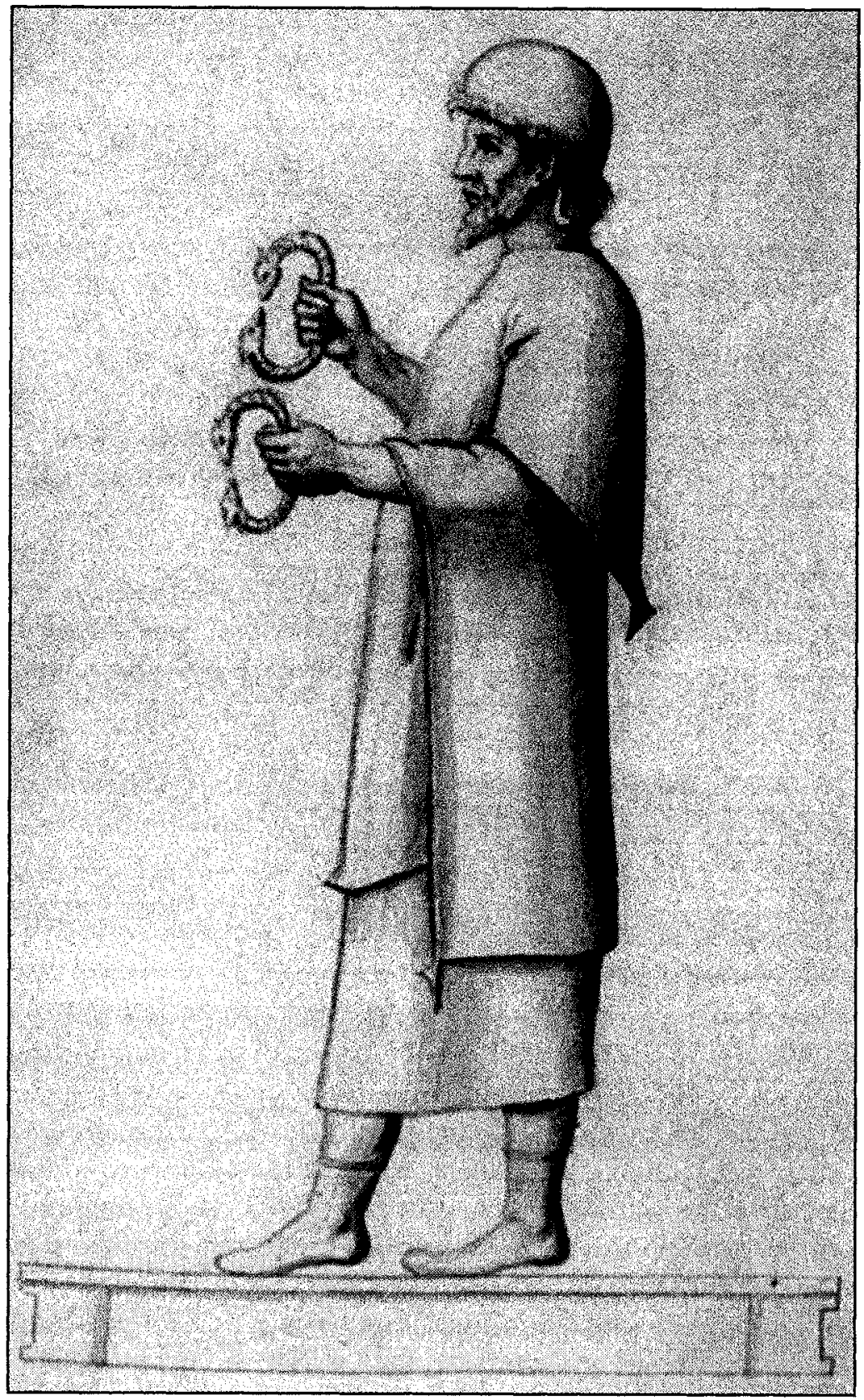

Figura 2. Dibujo de uno de los participantes en el cortejo de los relieves de Persépolis. EI dibujo, hecho a iniciativa del embajador, se conserva en los manuscritos (según A. Invernizzi, 2001, fig. 25) 


\section{Ex cursus: la identificación de Persépolis y la escritura de los antiguos persas}

M. Serrano y Sanz convirtió en capítulo VI del Libro Cuarto del manuscrito del embajador, el manojo de folios que hoy merece la mayor atención de los estudiosos, porque reúne una excelente descripción de las ruinas, su identificación razonada y la primera propuesta conocida de que los signos cuneiformes habrían sido la escritura propia de los antiguos persas ${ }^{34}$. El embajador habla de la gigantesca plataforma revestida de gruesos sillares de cantería, que apoyada en la ladera del Kuh-i Rahmat sirvió de base al conjunto de edificios, como una gruesa muralla de piedras de mármol «de maravillosa grandeza y de más de dos picas de altom. Al subir por las enormes escalinatas, notó el tamaño colosal y la perfecta talla de los escalones, y ya arriba, se asombró ante el pórtico "que sustentauan dos grandissimos cauallos de marmor blanco, mayor cada uno dellos que un gran elephante». A la derecha del pórtico contó veintisiete columnas que por "su mucha grandeza, ... llaman los persianos y arabes quarenta alcoranes» -quiere decir al minares-como las «torrezillas, ... que tienen en sus mezquitas principales», describiendo la planta y las filas de columnas de la que hoy sabemos que fue la apada$n a$, reparando en su enorme altura -que calcula «de sesenta hasta setenta pies de altura, sin la basa»-, el perfecto ajuste de los tambores y el no menos perfecto cuadrado de la sala. Describe luego su paseo por otros conjuntos de ruinas, y creo que llamó «lonjas» a los conjuntos que hoy designamos palacios de Darío, Artajerjes I, Jerjes, Artajerjes III, Palacio D y Tripylon, con sus relieves, puertas y marcos de ventanas tallados en mármoles y piedra negra, tan perfectamente pulidos que el gran mastín que acompañaba al embajador empezó a gruñir a su misma imagen reflejada "con mucha rrisa de los que estauan presentes». Los relieves le admiraron mucho, tanto por los tipos como por la perfección de la talla y su variedad, mandando a un pintor del séquito que sacara algunos dibujos del natural, los primeros tomados in situ por un profesional, aunque la mala fortuna haría luego que quedaran olvidados durante siglos en los manuscritos de la Biblioteca Nacional ${ }^{35}$. Siguiendo su paseo hacia la ladera, percibió el viajero otro edificio mucho mayor, con puertas y ventanas y numerosas columnas derribadas en el patio -probablemente se refería a lo que hoy llamamos Sala de las Cien Columnas-, notando luego que en los arquitrabes y frisos había inscripciones pintadas-como por desgracia todavía es hoy frecuente en las ruinas de todo el mundo- por visitantes árabes, armenios, indios y de otras naciones. Pero sobre todo fijó 
su atención en las inscripciones profundamente grabadas y labradas muy hondas en distintos sitios, como el «triunpho de la escalera», de las que mandó copiar un renglón, "cuyas letras, ...conpuestas todas de piramides pequeñas puestas de diferentes formas», estimando que éstas eran las escrituras de los antiguos constructores. Más allá, en plena ladera, sus acompañantes accedieron a las tumbas de Artajerjes II y Artajerjes III, y distinguieron la cisterna llena de agua limpia de las lluvias.

Acabada la descripción, Don García argumenta por qué piensa que Chilminara debía haber sido Persépolis, recurriendo tanto a las fuentes clásicas como a la evidencia visible y los informes que en España le había facilitado fray Antonio de Gouvea. Y concluye que esa fue la verdadera Persépolis reencontrada «la qual por tantos siglos a estado sepultada». La última anotación es de una melancólica y poética belleza, cuando dice que al anochecer, recogiéndose el embajador hacia Margascan, sobrevoló su séquito gran número de cigüeñas que a su vez volvían a los nidos instalados sobre las legendarias columnas.

\subsection{Un caballero en Isfahán y Qazvin, con su descubrimiento de un mun- do ignorado}

El viaje continuó hacia el noroeste, y en la segunda quincena de abril llegó a Isfahán, rodeada de huertas y jardines y ya entonces maravillosa ciudad, populosa y activa gracias al empeño del sha Abbás, que comenzó la mayor parte de los edificios que todavía hoy hacen su justa fama. Departió el embajador con los gobernadores de la ciudad, con los religiosos agustinos y carmelitas de sus conventos y con los europeos presentes «que eran diez ó doze ingleses, dos tudescos y tres ó quatro italianos, con quien el Enbaxador holgó mucho por saber algunas cosas de Europa». El primero de mayo hizo su entrada oficial, acompañado de mucha gente a caballo. Pasó por barrios semejantes a los de Shiraz, hasta que llegó al gran bazar abovedado y con luz cenital, de donde salió a la enorme plaza de Maidan, "de mas de seiscientos pasos de largo y trezientos de ancho", sus magníficas mezquitas todavía en construcción y el palacio, "con una lonja quadrada á la entrada, cubierta con su boveda, y una varanda encima", todo magnífico y famoso ejemplo de la arquitectura del periodo ${ }^{36}$ y fruto del empeño del sha. Aquellos grandes edificios y espacios le gustaron mucho al embajador, que los describió minuciosamente, pues ya era Isfahán la cabeza principal del imperio, en la que convivían persas, armenios, 
georgianos y otras naciones, siendo maravilla la variedad de vestidos y tipos, que el color y la luz de los azulejos y las ilustraciones de libros y miniaturas safavíes nos permiten aún hoy imaginar. Pero a los pocos días de estancia recibió orden del sha para que fuese a Qazvin, a donde llegó el 15 de junio, acercándose a la ciudad con todo el cortejo vestido de gala y a caballo, e instalándose en la casa que se le había asig. nado. Dos días después se dirigieron el embajador y los suyos a la recepción ofrecida por el sha, precedidos por más de seiscientos hombres portadores de los regalos enviados por el rey de España, pasando por la ciudad con gran pompa y camino del palacio y jardines donde comenzaba este artículo. Durante la cena Don García notó que el sha iba a ser un difícil contendiente, y que la presencia del embajador turco también invitado formaba parte de su juego. Aunque Abbás brindó por dos veces, a la salud del rey de España "su hermano", y como bienvenida del embajador. Luego los contactos se dilataron, sin que Don García tuviera ocasión de plantear el objeto principal de su embajada - animar la continuación de la guerra contra el turco-, sospechando con razón que los planes del sha eran ahora distintos. Por fin consiguió su propósito y hablaron largo y tendido pero sin resolución final, pues Abbás se quejaba siempre de la poca actividad de los europeos en contra de los turcos, sin dejarle tocar al español el tema de las recientes conquistas persas en los presidios portugueses. Se prolongó la estancia y Don García asistió un día a una partida de polo jugada en la plaza por el rey y los suyos, teniendo ocasión de ver una escena que las miniaturas safavíes gustaron repetir sobre libros y objetos muy diversos. Poco después el monarca salió de Qazvin, y mandó a Don García que se volviera a Isfahán y le esperara allí. Partido el español el $27 \mathrm{de}$ julio de 1618, llegó de vuelta a la nueva capital del sha el 13 agosto, donde habría de pasar todo el invierno, asistiendo a las ceremonias tradicionales en recuerdo de la muerte de Hussein, propias de los chiíes, fiestas y ritos que describe con notable detalle y respetuosa atención. Vuelto por fin el sha, hubo entre otras celebraciones una última entrevista en la misma plaza de Maidam. Y por fin, Don García recibió autorización para marchar, lo que hizo el 25 de agosto de 1619, aún encontrándose enfermo, llegando a la costa y embarcándose para Ormuz el 18 de octubre. Con gran pesar suyo tuvo que invernar allí, dándole tiempo a notar que las gestiones llevadas a cabo habían tenido escaso fruto, y que los persas se preparaban incluso para tomar $\mathrm{Or}$ muz. 
Un caballero español en Isfahán...

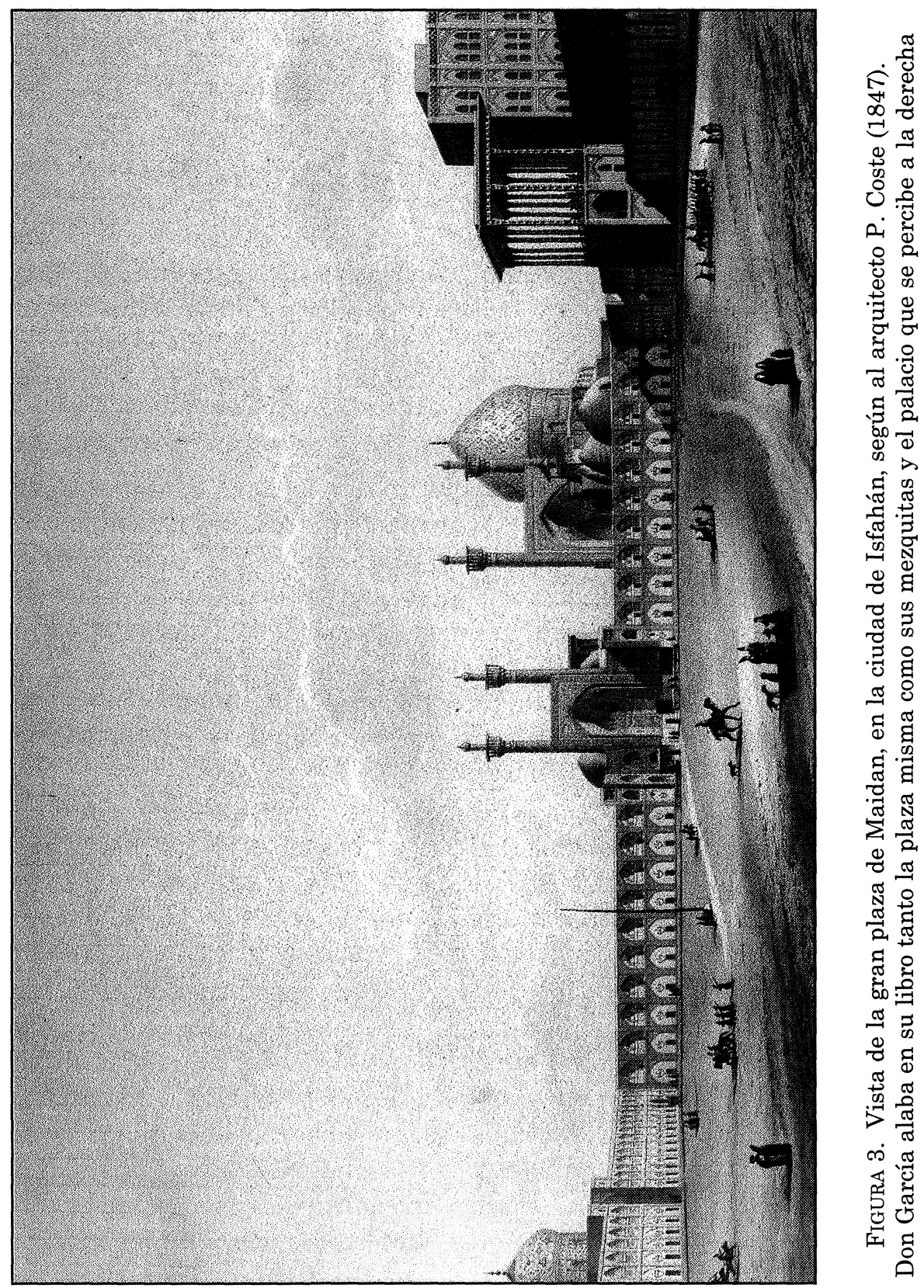




\section{La agonía del retorno y un epílogo en la calma de los dioses}

El final de su más que extremada aventura se aproximaba, aunque no en la forma que Don García deseaba. Tras peligrosa navegación llegó a Goa el 25 de abril de 1620, encontrando la misma falta de colaboración antes sufrida. Un primer intento de tornar a España, embarcándose el 19 de diciembre de ese mismo año, resultaría en amargo fracaso, pues después de un peligroso viaje y haber alcanzado las costas de Mozambique en febrero, sabiendo el piloto que por el régimen de vientos y corrientes ya no podrían pasar el Cabo de Buena Esperanza hasta diciembre, el 14 de febrero de 1621 resolvieron volver de nuevo a Goa, donde arribaron un 28 de mayo. Don García retomó sus Comentarios, reiterando páginas llenas de interesantes observaciones, narrando la temida guerra de Ormuz y los combates contra ingleses y holandeses.

Por fin, el 1 de febrero de 1624 pudo hacerse de nuevo a la mar con vientos favorables, y a pesar del mal gobierno de la nave y de ir ésta sobrecargada, se siguió adelante. En sus últimas anotaciones reflexiona sobre la desidia de los pilotos lusos, lamentando que por el contrario «los marineros estrangeros , ...todo lo rreconoçen y lo sondean con especial diligencia». El 13 de abril se conoció hallarse al este de la Tierra de Natal, aunque el piloto decía haber doblado ya el Cabo, lo que ciertamente no se haría hasta el 25 de abril. La última anotación del embajador es de tres días después, indicando rumbo noroeste, con el sol en $32^{\circ}$ y medio. Fue su última anotación.

El Ms 17629 de la Biblioteca Nacional tiene una acotación final estremecedora. Dice que Don García siguió escribiendo cada día hasta casi el de su muerte, «que sucedió en su buelta a España, á 22 de julio de 1624, á las ocho horas de la noche, del Mal de Loanda, en $35^{\circ}$ de norte, ciento y diez leguas de las islas de Flores y Cuervo. Hecharon su cuerpo á la mar, en un caxón cargado de piedras, y andó en calmerías alrededor de la nao dos días». La situación debió ser trágica. Era como si incluso tras la muerte, aquel buen caballero no quisiera apartarse del barco que había estado a punto de cumplirle su anhelado deseo de vuelta a España. Y quedó así, como dice la nota, flotando durante dos días en una mar en calma, lisa, dramática para quienes desde la nave siguieron viendo su improvisado ataúd. $\mathrm{Al}$ evocarlo así, algo me hace recordar los bien conocidos versos de Paul Valéry, y repetirlos ahora como oración merecida en su recuerdo: "Ce toit tranquille, oú marchent des colombes / Entre les pins palpite, entre les tombes; / Midi le juste y compose de feux / La mer, la mer, toujours recommencée! / O récompense après une pensée / Qu'un 


\section{Un caballero español en Isfahán...}

long regard sur le calme des dieux! $\aleph^{37}$. Y luego, poco a poco, su ataúd se fue hundiendo lentamente en las profundidades del Océano Atlántico.

\section{Notas}

${ }^{1}$ La edición de Wicqfort es un atractivo volumen de $506 \mathrm{pp}$, más algunas de preliminares, cuyo título completo es L'Ambassade de D. Garcias de Silva Figveroa en Perse, contenant la Politique de ce grand Empire, les moeurs du Roy Schach Abbas, \& vne Relation exacte de touts les lieux de Perse \& des Indes, oú cet Ambassadeur a esté l'espace de huit années qu'il y a demeuré. Traduite de l'Espagnol. Par Monsieur De Wicqfort. A Paris, Chez Jean Dv Pvis, rüe S. Iacques, à la Couronne d'Or. M.DC.LXVII. Avec privilege du Roy. Don Manuel Serrano y Sanz, el primero y hasta ahora único editor de uno de los manuscritos conservados de la relación del viaje del embajador español -véase obra citada más adelante en la nota $\mathrm{n}^{\circ} 4$, p. VII-, ya puso de relieve que la copia manuscrita usada por Wicqfort estaba incompleta, falta de los tres primeros libros que relatan el viaje por mar, cuya existencia el editor francés debía ignorar, si fue sincera su afirmación de que la relación empezaba en Goa y parecía estar "desfigurada de una o dos hojas en su inicion.

${ }^{2}$ Voyages de Mr. Le Chevalier Chardin, En Perse, et autres lieux de l'Orient. A Amsterdam, Chez Jean Louis de Lorme. MDCCXI, edición en 10 volúmenes. Véase vol. III, p. 119.

${ }^{3}$ InvernizZI, A. (ed.) (2005): Il Genio vagante. Babilonia, Ctesifonte, Persepoli in racconti di viaggio e testimonianze dei secoli XII-XVIII. Edizioni dell'Orso s.r.l., Alessandria. En un volumen de gran formato -y que deja para más adelante la literatura del siglo XIX, en 608 pp. de texto a dos columnas, más 294 láminas, se recogen datos bio-bibliográficos de 211 autores y viajeros y una amplia antología de sus obras, particularmente las páginas dedicadas a las legendarias ciudades y monumentos citados en el subtítulo de su antología. Pues bien, el Prof. A., Invernizzi, quizás el más prestigioso especialista moderno en literatura de viajes a Oriente, dedica incluso más páginas Don García de Silva (pp. 205-221) que a su con razón bienamado y estudiado compatriota, el gran Pietro della Valle (pp. 193-204).

4 Serrano y Sanz, M. (ed.) (1903-1905) : Comentarios de D. García de Silva y Figueroa de la embajada que de parte del rey de España Don Felipe III hizo al rey xa Abas de Persia. Sociedad de Bibliófilos Españoles, Madrid 1903 (vol. I), Madrid 1905 (vol. II). El primer volumen, de 397, incluye otras XVIII con un interesante estudio del editor y los libros $1^{\circ}$ al $4^{\circ}$. El segundo, de 625 pp., los libros $5^{\circ}$ al $8^{\circ}$. Es interesante notar que entre los 187 miembros de la Sociedad de Bibliófilos Españoles listados al final del primer volumen figuran entidades y personas tan curiosas como la Biblioteca de la Universidad de Bonn, la Imperial de Strassburgo y Otto Harrasowitz de Leipzig entre otros muchos.

5 GABRIEL, A. (1969) : Vergessene Persienreisende. Verlag Notring, Wien, p. 2. Estudia a viajeros realmente olvidados y singulares, como von Poser, Petits de la Croix, Hanway, Fraser, Stocqueler, Aucher, Layard, Floyer, Gasteiger y Wilson.

${ }^{6}$ Gil FernÁndez, L. (ed.) (1989): García de Silva y Figueroa. Epistolario diplomático. Edición y estudios preliminares de Luis Gil. Institución Cultural El Brocense, Cáceres. La valiosísima colección de documentos transcriptos (biográficos, 1 al 10: epistolario di- 
plomático, 11 al 41: consultas y dictámenes, 42 al 79 y apéndices, 80 al 71), va precedida de dos estudios preliminares: una corta semblanza del embajador (pp. 25-31), y una amplia consideración de las relaciones hispano-persas (pp. 33-165), pero sólo dedica a las gestiones de Don García un pequeño espacio (pp. 153-165). En todo caso se trata de un libro de excepcional valor, que honra el esfuerzo meritorio de su autor y su perfecto conocimiento de la política de la época.

7 Sancisi-Weerdendura, H. (1991) : «Introduction. Through travellers' eyes: the Persian monuments as seen by European travellers", en H. SANCISI-WEERDENBURG \& J. W. DRIJVERS (eds.): Achaemenid History VII. Through Travellers' Eyes. European Travellers on the Iranian Monuments. Nederlands Instituut voor het Nabije Oosten, Leiden, pp. 135. Sobre García de Silva véanse pp. 5-6. La autora -que siempre cita la edición de Wicqfort-, dice que el texto menciona que el embajador mandó a un artista tomar algunos dibujos, que la primera edición no contiene y que «nothing is known at present of the fate of these drawings".

8 Alonso, C. (1993): La embajada a Persia de D. García de Silva y Figueroa (16121624). Departamento de Publicaciones, Excma. Diputación Provincial de Badajoz, Badajoz. Publicado como vol. 14 de una colección de Biografias Extremeñas, la obra no ha alcanzado la difusión que merece, quizás por simples problemas de distribución. El título que cito arriba es el que aparece en la portada interior. En la exterior se ofrece otro que difiere ligeramente: "D. García de Silva y Figueroa. Embajador en Persia", tal vez por adecuarlo al tono de la colección.

${ }^{9}$ CóRDobA, J. M (1994): «Algunas notas obre Don García de Silva y el descubrimiento del Oriente a comienzos del siglo XVII", en J. MANGAS y J. ALVAR (eds.) Homenaje a José $\mathrm{M}^{a}$ Blázquez. Ediciones Clásicas, Madrid, vol. I, pp. 353-361. CóRDoBA, J. Ma (2001) : «La percepción del Irán antiguo y contemporáneo en la obra de los viajeros españoles de los siglos XVII y XIX", en J. Ma CóRdoba, R. JIMÉnez ZAMUdio, C. SEvilLa CUEVA (eds.) El Redescubrimiento de Oriente Próximo y Egipto. Viajes, hallazgos e investigaciones. Universidad Autónoma de Madrid, Madrid, pp. 1-16. Igualmente existe información didáctica en la página web del Centro Superior de Estudios de Oriente Próximo y Egipto antiguos de la UAM: www.uam.es/ceae en el apartado de «Proyectos», el punto IX del relativo a "Ciclos de Estudios sobre Oriente».

${ }^{10}$ InvernizZI, A. (ed.) (2001): Pietro della Valle. In viaggio per l'Oriente. Le mummie, Babilonia, Persepoli. Edizioni dell'Orso S.r.l., Alessandria. Sobre los dibujos tomados en Persépolis por Silva y Figueroa pp. 71-79 y figs. 20 a 30.

11 Invernizzi, A. (ed.) (2005): op. cit.. Como indico más arriba -véase nota n 3-, A. Invernizzi dedica diecisiete páginas a García de Silva (pp. 205-221) y doce a Pietro della Valle (pp. 193-204), lo que no deja de ser todo un síntoma del valor que concede a los comentarios del embajador español.

12 Por ejemplo, en un reciente trabajo, Fernando Marías relaciona el mapa de Goa conservado en el Ms. 18217 con las descripciones hechas de la ciudad. Así MARÍA, Fdo. (2002): «Don García de Silva y Figueroa y la percepción del Oriente: la «Descripción de Goa», Anuario del Departamento de Historia y Teoría del Arte (U.A.M.), vol. XIV, pp. 137-149.

13 Silva y Figueroa, G. de (en prensa): Comentarios. Los viajes por los océanos Atlántico e Índico, Goa y las costas de Arabia y Omán de un embajador español, con sus jornadas por el corazón de Persia y la descripción amena de Persépolis, Isfahán o Babilonia, los paisajes y las costumbres de Irán y de muchos otros monumentos y pueblos. Estudio, antología y notas a cargo de J. $\mathrm{M}^{\mathrm{a}}$ Córdoba. Miraguano S. A. Ediciones, Madrid. 


\section{Un caballero español en Isfahán...}

14 Así lo deja entrever, sin declararlo expresamente su editor español por el contenido y tono de la introducción a su edición: SERraNo y SANZ, M. (ed.) (1903-1905): op. cit., vol. I, pp. IV-XVIII. Con claridad lo indica GIL FERNÁNDEZ, L. (ed.) (1989) : op. cit. p. 25. Y tácitamente la permite traslucir ALONSO, C. (1993): op. cit., pp. 21-26.

15 Serrano y Sanz, M. (ed.) (1903-1905): op. cit., vol. I, pp. VI-VII. Gil Fernández, L. (ed.) (1989): op. cit., p. 26. Alonso, C. (1993): op. cit., p. 21.

16 «Silva y Figueroa, Don García», Enciclopedia Ilustrada Hispano-Americana Espasa, Vol. 56, p. 263. Los datos relativos a su condición de paje de Felipe II y su servicio en las guerras de Flandes que aparecen en este artículo son los que considera C. Alonso de «informadores incontrolados» (op. cit., p. 22). Bien es cierto que hasta ahora al menos no han sido corroborados por documentación alguna, pero el autor del artículo de enciclopedia tan prestigiosa como la Espasa debió tener algo a la vista, o basarse en deducciones historiográficamente legítimas. Su paso por Salamanca lo recuerda M. Serrano y Sanz en su nota 4 (op. cit.,Vol. I., p. V-VI), amparándose en el bibliógrafo Vicente Barrantes y en Vivas Tabero; pero la formación humanística y política, el conocimiento de lenguas y las demás virtudes que el embajador demuestra en su viaje, correspondencia y obra no corresponden a la semblanza que según los críticos sería la única posible: un hidalgo de provincias, poco hábil en la explotación de su hacienda, que a los 46 años se ve nombrado corregidor de Jaén. La verdad, aunque la documentación sea escasa, los elementos de juicio y el mismo sentido del historiador permiten avanzar algo más en la reconstrucción de una imagen biográfica.

17 De su notable cultura habla sobradamente el contenido de sus Comentarios y el de su correspondencia e informes. C. Alonso cita la estima que de Don García manifiesta el famoso Antonio Bocarro en su nota 8 (op. cit., p. 22) que me permito remitir: «(8) Antonio Bocarro, Década 13 da Historia da India, ed. De Rodrigo José de Lima, Felner, vol. I, Lisboa 1876, p. 370).

18 Véase el documento relativo al problema del mayorazgo que manda Don García a Felipe II en Gil Fernández, L. (ed.) (1989): p. 170, Doc. $n^{\circ} 3$ Silva a Felipe II (autógrafa, 1596), AGS, C.C. pers. 27.

19 «Silva y Figueroa, Don García», Enciclopedia Ilustrada Hispano-Americana Espasa, Vol. 56, p. 263. Serrano y SANZ, M. (ed.) (1903-1905): op. cit., vol. I, p. V.

${ }^{20}$ Gil Fernández, L. (ed.) (1989): p. 27. Los Comentarios están llenos de observaciones de todo tipo que revelan inequívocamente la visión y los conocimientos de geógrafo.

21 Lo llamativo de la excelente edición documental de Luis Gil es, precisamente, la minuciosa y detallada atención que dedica a la historia de las relaciones diplomáticas entre España e Irán y los precedentes inmediatos a la embajada de Don García de Silva, en contraste con las páginas dedicadas a la misión diplomática en sí, pero ello no desmerece en absoluto la calidad y el interés de este libro excepcional. Véase GIL FERNÁNDEZ, L. (ed.) (1989), pp. 33-152.

22 GIL Fernández, L. (ed.) (1989): op. cit., p. 154. El documento de aceptación y los sucesivos escritos preparatorios son ya de por sí una evidencia manifiesta de la profunda comprensión que el recién nombrado embajador tenía de la importancia política de la misión y de la minuciosidad con la que se había de preparar: véase op. cit., pp. 181 y 182, Docs. $n^{\circ} 11$ y n $^{\circ} 12$.

${ }^{23}$ Luis Gil Fernández trata con todo detalle las pugnas, disputas y las supuestas afrentas a las "competencias" lusas -op. cit., véase nota 21-: lo chocante del caso es que conduc-

ta tan estúpida políticamente iba tan en detrimento de los propios intereses del imperio portugués, que el mismo sha llegó a reconvenirles por «puentear» al embajador de su legí- 
timo rey y hablar en nombre de Portugal y no de España, y "se admirava mucho de que su Magestad permitiese esto, pues era tan contra su rreputaçión y tanbien de los mesmos portugueses, gastando muchas palabras sobre el caso; mas aunque lo que el rey de Persia dezia era tan cierto y lo es, que podria nazer de lo contrario muy grandes inconvenientes, no solo aborreçen la vnion con la monarchia de España, pero por ningun caso quieren nombrarse ni ser tenidos por españoles" (Comentarios, vol. II, pp. 360-361). Lo dramático del caso es que conductas tan "inteligentes» y que nos llevaron al desastre común a mediados del siglo XVII, resurgen con necedad parecida y aún mayor, en los abundantes ejemplos que la pequeña política de nuestro país nos ofrece casi a diario y con tan asombrosa facundia.

24 Serrano y Sanz, M. (ed.) (1903-1905): op. cit., vol. I, p. XVIII.

25 Serrano y SANZ, M. (ed.) (1903-1905): op. cit., vol. I. El viaje ocupa todo el Libro Primero, que en la edición de referencia puede leerse entre las páginas 1 y 126 , ordenado por su editor en cinco capítulos. En mi exposición voy siguiendo los avatares narrados por el embajador español, y meto entre comillas algunas citas que me parecen ilustrativas, respetando la especial ortografía de la época y el manuscrito, como hizo el editor, sin reiterar además una nota expresa a cada cita en este listado, por el deseo apuntado de aligerar en lo posible el aparato. No obstante, cualquier interesado podrá hallarlas fácilmente en las páginas de la edición de Serrano y Sanz, siguiendo el calendario de la navegación que el embajador va anotando minuciosamente.

${ }^{26}$ SOLER, I. (2004): Los mares náufragos. Acantilado, Barcelona, pp. 10-11 y mapa en pp. 50-51.

27 Después de describir su tamaño, pico, plumaje y patas observa que «no se quejó ni hizo mouimiento alguno despues de preso. El Embaxador le mandó soltar y luego que se sintió libre se sentó en el agua debaxo del mesmo corredor, a donde sin apartarse anduuo nadando gran ratom SERRANo y SANZ, M. (ed.) (1903-1905): op. cit., vol. I, p. 32.

${ }^{28}$ Aunque durante el viaje por mar Don García de Silva debió ya tomar notas y escribir muchas de sus impresiones, el manuscrito de su primer libro se cierra algunos meses después de su estancia en tierra, con la anotación Goae, IV Kalendas Februarii 1615.

29 Serrano y Sanz, M. (ed.) (1903-1905): op. cit., vol. I, el Libro Segundo lo dividió el editor en cuatro capítulos -pp. 127-218-, y el Libro Tercero en sólo dos -pp. 219-269. mantengo ahora y en lo sucesivo los criterios de comentario y cita indicados en la nota 24 .

30 GIL FERnÁNDEZ, L. (ed.) (1989): op. cit.. Véanse en el apartado IV Epistolario Diplomático (Núms. 11-41), pp. 179-248, además de otras dirigidas a distintos corresponsales, las diez largas cartas del embajador transcriptas y las respuestas del monarca. Las del embajador son, desde luego, del mayor interés.

31 Como se ha dicho más arriba, este mapa y los Comentarios del embajador han dado pie al trabajo citado de MARÍAS, Fdo. (2002): op. cit., pp. 137-149, que se lee con verdadero interés.

32 El Libro Tercero lo dividió Serrano y Sanz, M. (1903-1905): op. cit. Vol. I, en dos capítulos, tratando en el primero -pp. 218-242-, además de sus diferencias con el virrey como se ha dicho, la salida de Goa, la navegación hasta Mascate y la descripción de esta ciudad. En el segundo -pp. 242-269-, la navegación por la costa de Arabia y la llegada y estancia en Ormuz. Y por fin, en el Libro Cuarto - de cuyo original toma el editor una parte dividiéndola en seis capítulos -pp. 270-394-, Don García llega a Irán y va describiendo su viaje hasta Shiraz, sin olvidar la célebre descripción de Persépolis que el editor convierte en capítulo quinto. En su segundo volumen, publicado en 1905 , el editor recogió -y titulándolo Quinto- la segunda parte del Libro Cuarto del original de Don García -pp. 7 153-, y los restantes libros Quinto, Sexto y Séptimo del manuscrito, que el editor nume- 


\section{Un caballero español en Isfahán...}

ra sexto, séptimo octavo. Se recogen en este volumen el paso por Isfahán, Qum, la llegada a Qazvin y la entrevista con el sha, una larga disgresión histórica sobre Irán, Tamerlán y Mesopotamia (Libro Quinto / sexto del editor, pp. 155-305), la salida de Qazvin y nueva estancia en Isfahán, las fiestas persas y la vuelta hasta Goa (Libro Sexto / séptimo del editor pp. 307-498). Sigo el relato del viaje transitando por el libro de Don García, y excusándome de reiterar las notas referidas a su texto por lo anteriormente apuntado.

33 Dice Don García que en la distancia se veían sobre la cumbre de las montañas pequeños «montecillos», con la forma de las parvas de trigo o cebada como solía hacerse en España Serrano y SANZ, M. (1903-1905): op. cit. Vol. I, p. 229. Creo que quizás se refería a las sepulturas de piedra tipo colmena (beehive-type graves) de Omán, fechadas en el III milenio: véase PotTs, D. T. (1992): The Arabian Gulf in Antiquity. Volume I. From Prehistory to the Fall of the Achaemenid Empire. Clarendon Press, Oxford, pp. 74-78.

34 Serrano y Sanz, M. (1903-1905): op. cit. Vol. I, pp. 372-394. Para una descripción reciente de las ruinas e identificación última de sus distintos edificios, magníficamente ilustrada y documentada, véase KocH, H. (2001): Persepolis. Glänzende Hauptstadt des Perserreichs. Verlag Philipp von Zabern, Mainz am Rhein.

${ }_{35}$ Publicados en la edición de M. Serrano y Sanz, A. Invernizzi los ha puesto en su justo valor en el libro arriba citado, INVERNIZZI, A. (2001): op. cit., pp. 71-79 y figuras 20-30.

${ }^{36}$ Sobre la arquitectura y el arte en general del periodo safaví, puede verse el capítulo firmado por varios autores y titulado «Irán: safávidas y qayaríes», en la obra colectiva Hattstein, M. y Delius, P. (eds.) (2001): El Islam. Arte y arquitectura. Könemann Verlagsgesellschaft mbH, Colonia, pp. 494-533. El plano general de las intervenciones del sha Abbás puede verse en la figura correspondiente de la p. 509.

37 Repito el texto ofrecido en la edición VELÉRY, P. (1970): El cementerio marino. Alianza Editorial, Madrid, con prefacio del mismo poeta y un ensayo de explicación de Gustave Cohen, en traducción de Jorge Guillén. Estos versos se publican en la página 40. Aunque la traducción parece excusada por la limpieza del lenguaje, es obligado copiar la que J. Guillén ofrece en la p. 41: «Ese techo, tranquilo de palomas, / Palpita entre los pinos y las tumbas. / El Mediodía justo en él enciende / El mar, el mar, sin cesar empezando ... / Recompensa después de un pensamiento: / Mirar por fin la calma de los dioses». 